3 Shaper AG, Pocock SJ, Walker M, Cohen NM, Wale CJ, Thomson AG. British Regional Heart Study: cardiovascular risk factors in middle aged men in 24 towns. Br Med 7 1981;283:179-86. 4 Shaper AG, Cook DG, Walker M, Macfarlane PW. Recall of diagnosis by men with ischaemic heart disease. Br Heart $\mathcal{O}$ 1984;51:606-11.

5 Walker $M$, Shaper AG. Follow-up of subjects in prospective studies in general practice. $\mathcal{F} R$ Coll Gen Pract 1984;34:365-70.

6 Shaper AG, Pocock SJ, Walker M, Phillips A, Whitehead TP, Macfarlane PW. Risk factors for ischaemic heart disease: the prospective phase of the British Regional Heart Study. I Epidemiol Community Health 1985;39:197-209.

7 Shaper AG. Geographic variations in cardiovascular mortality in Great Britain. Br Med Bull $1984 ; 40: 366-73$.

8 World Health Organisation. Prevention of coronary heart disease. Geneva: WHO, 1982. (Technical Report Series No 678.)

9 Rose G. Strategy of prevention: lessons from cardiovascular disease. Br Med $\mathcal{J} 1981 ; 282: 1847-51$. 10 Anonymous. Consensus conference: lowering blood cholesterol to prevent heart disease. fAMA

1985;253:2080-6.
11 Oliver MF. Strategies for preventing and screening for coronary heart disease. Br Hean $\mathrm{f}$ 1985;54:1-5.

12 Thelle DS, Shaper AG, Whitehead TP, et al. Blood lipids in middle aged British men. Br Hear f 1983;49:205-13.
13 Shaper AG, Pocock SI. British blood cholesterol values and the American consensus. Br Med 7 1985;291:480-1.

14 Kornitzer M, De Backer G, Dramaix M, et al. Belgian heart disease prevention project: incidence and mortality results. Lancet 1983; i: 1066-70.

15 Davies MJ, Thomas AC. Review: plaque fissuring - the cause of acute myocardial infarction, sudden ischaemic death, and crescendo angina. Br Heart $\mathcal{1}$ 1985;53:363-73.

16 Meade TW, Chakrabarti R, Haines AP, North WRS. Characteristics affecting fibrinolytic activity and plasma fibrinogen concentrations. BrMed $\mathcal{J}$ 1979;i:153-6.

17 Medical Research Council Working Party. MRC trial of treatment of mild hypertension; principal results. Br Med f 1985;291:97-104.

18 Taber L, Fagerberg CJG, Gad A, et al. Reduction in mortality from breast cancer after mass screening with mammography. Lancet $1985 ; 1: 829-32$.

19 Committee on Medical Aspects of Food Policy, Panel on Diet in Relation to Cardiovascular Disease. Diet and cardiovascular disease. London: DHSS, 1984.

20 Joint Working Party of the Royal College of Physicians of London and the British Cardiac Society. Prevention of coronary heart disease. $f R$ Coll Physicians Lond 1976;10:213-75.

\title{
Effect of chorionic villus sampling and early pregnancy counselling on uptake of prenatal diagnosis
}

\author{
P D KNOTT, R H T WARD, M K LUCAS
}

\begin{abstract}
An early pregnancy counselling clinic was introduced to improve the uptake of prenatal diagnosis and to offer chorionic villus sampling to women aged 38 and over by their expected date of delivery. Ninety eight $(62 \%)$ unselected older mothers were seen before 11 weeks' gestation, and $23(32 \%)$ of those with viable pregnancies elected to undergo chorionic villus sampling compared with $38(52 \%)$ electing amniocentesis. A quarter of the patients booking before 11 weeks had a miscarriage.

Because of the future potential demand for chorionic villus sampling counselling during pregnancy and referral of eligible patients should occur as early as possible.
\end{abstract}

\section{Introduction}

Although the association between Down's syndrome and maternal age was established by Penrose in 1933, ' it was not until 1966 that successful karyotyping from cells in amniotic fluid was reported. ${ }^{2}$ Since then amniocentesis has become widely available to older mothers for prenatal diagnosis. Although the newer techniques monitored by ultrasound have reduced complications, ${ }^{3}$ the risk to the fetus is still estimated to be about $0.5 \%$.

The major disadvantage of amniocentesis is that it is most safely performed after 16 weeks' gestation so that termination of pregnancy, if necessary, is late, which has associated disadvantages. This may be a reason for the uptake of amniocentesis in the population at risk being lower than expected. ${ }^{6}$ Chorionic villus sampling was introduced at University College Hospital for the diagnosis of thalassaemia in 1982, but more recently the technique

Department of Obstetrics and Gynaecology, Faculty of Clinical Sciences, University College London, London WC1E 6HX

P D KNOTT, MRCOG, research fellow in perinatology

R H T WARD, MA, FRCOG, consultant obstetrician

Galton Laboratory, Department of Genetics and Biometry, Wolfson House,

University College London, London NW1 2HE

M K LUCAS, MB, DCH, consultant clinical geneticist

Correspondence to: Dr Knott. has also been used as an alternative to amniocentesis for genetic screening. We studied the impact of introducing fetal diagnosis during the first trimester for mothers at risk of delivering a chromosomally abnormal baby due to advanced age.

\section{Patients and methods}

At University College Hospital prenatal diagnosis is offered to all patients who will be 38 or over by their expected date of delivery. These mothers are seen at a special booking clinic within one week of referral to the hospital for antenatal care. Before counselling and the booking interview an ultrasound scan is performed to determine gestational age and exclude multiple or nonviable pregnancies.

The patient and her partner (if present) are then seen by one of two counsellors (PK and ML). If the pregnancy is of less than 11 weeks' gestation they are offered a choice of chorionic villus sampling, amniocentesis, or no test. They are told about the risks of a chromosomal abnormality and the advantages and disadvantages of the tests available. During this study we quoted the risks of miscarriage as being $0.5 \%$ greater than the background incidence of miscarriage for amniocentesis and $1-2 \%$ greater for chorionic villus sampling (based on local and international experience). Patients are also told that chorionic villus sampling occasionally fails to produce a result but that in these circumstances amniocentesis is still possible. They are then allowed to consider their decision at home before any tests are arranged.

Chorionic villus sampling is performed between the eighth and completed 10 th week of gestation by the transcervical route with the Portex catheter and the method previously described by Ward et al. ${ }^{8} \mathrm{~A}$ maximum of two attempts at aspiration are made on any one day. Amniocentesis is performed between 16 and 18 weeks. A pool of fluid is selected and a $22 \mathrm{G}$ spinal needle directed into the pool with continuous ultrasound surveillance. Amniotic fluid $(20 \mathrm{ml})$ is withdrawn and the cells are removed for culture.

Although direct preparations are possible from chorionic villus samples, at University College Hospital we culture the cells obtained from both procedures. The results are therefore available to the patients two to three weeks after the tests are performed. All patients who undergo chorionic villus sampling have an ultrasound scan at 18 weeks to exclude fetal abnormality, and thereafter the pregnancies are monitored in the antenatal clinic in the usual way.

\section{Results}

Since the introduction of the early pregnancy counselling clinic at University College Hospital 157 patients eligible for prenatal diagnosis have booked appointments. Of these, $98(62 \%)$ were seen before 11 weeks' 
gestation and were therefore potential candidates for chorionic villus sampling. Eighteen of these patients had a non-viable pregnancy at booking and seven aborted spontaneously before testing, giving a loss in this group of $26 \%$. Among the 59 patients booking after more than 11 weeks' gestation there were only three losses before testing leaving a total of 129 patients with continuing pregnancies, to whom tests were offered.

The table shows the uptake of prenatal diagnosis, with a total of 105 patients $(81 \%)$ electing to be tested. Chorionic villus sampling was successful in achieving a diagnosis in 21 of 23 patients tested, but one patient aborted a normal fetus four weeks after an uncomplicated procedure. Two chorionic villus sampling procedures failed to obtain an adequate sample; one of the patients aborted five days afterwards with ruptured membranes and the other delivered normally after an uncomplicated amniocentesis. The 82 patients electing amniocentesis all obtained a result after the first tap and none subsequently aborted.

Tests chosen by older mothers with continuing pregnancies (figures are number (percentages) of mothers)

\begin{tabular}{lccc}
\hline & \multicolumn{2}{c}{ Gestation at time of booking } & \\
\cline { 2 - 3 } & $<11^{11}$ & Total \\
\hline No test & $12(16)$ & $12(21)$ & $24(19)$ \\
Chorionic villus sampling & $23(32)$ & $44(79)$ & $82(64)$ \\
Amniocentesis & $38(52)$ & $56(100)$ & $129(100)$ \\
\hline Total & $73(100)$ & & \\
\hline
\end{tabular}

\section{Discussion}

The uptake of amniocentesis at University College Hospital increased steadily from $32 \cdot 2 \%$ in 1980 to $63 \cdot 1 \%$ in $1984 .{ }^{6}$ This trend is almost certainly due to increased public awareness of the availability of prenatal diagnosis. Since the introduction of the clinic, however, the uptake of prenatal diagnosis has suddenly increased to $81 \cdot 4 \%$, which compares favourably with the results reported from other countries reviewed by Baird et al. ${ }^{9}$ Whether this effect is due to the clinic or the availability of earlier diagnosis is uncertain, but it is pertinent to note that the uptake of amniocentesis in this series $(63.6 \%)$ is very similar to that in 1984 .

A high proportion of non-viable pregnancies was diagnosed at the booking visit, especially in patients of less than 11 weeks' gestation. Older women have an increased risk of spontaneous abortion, ${ }^{10}$ and diagnosis by ultrasound before booking at the antenatal clinic at least saves patients the emotional trauma of unnecessary preparation for hospital care and allows them the choice of being admitted for evacuation of the uterus.

Perhaps the major problem of introducing chorionic villus sampling into the screening programme for older women is that many patients are not seen early enough in pregnancy. Only 98 $(62 \%)$ of our patients were seen at less than 11 weeks' gestation despite their being a relatively high risk group for other obstetric complications as well as for a fetus with Down's syndrome. Awareness among general practitioners that diagnosis during first trimester is possible should help to increase its availability to the patients, and this in turn may increase the proportion of patients electing to be tested. It is also essential at this stage that chorionic villus sampling should be properly evaluated against amniocentesis, ${ }^{11}$ and early referral of patients will help this to be done quickly and efficiently.

Our thanks to the staff of University College Hospital antenatal clinic for their help and interest, and to Heather Cooke for her work on the chorionic villus samples. Peter Knott is supported by the Sir Jules Thorn Charitable Trust. The ATL sector scanner used for chorionic villus sampling was financed by the Department of Health and Social Security.

\section{References}

1 Penrose LS. The relative effects of paternal and maternal age in mongolism. Journal of Genetics $1933 ; 27: 219-24$

2 Steele MW', Breg WR. Chromosome analysis of human amniotic-fluid cells. Lancet 1966; ; 383 -5.

3 Romero R, Jeanty P, Reece EA, et al. Sonographically monitored amniocentesis to reduce intraoperative complications. Obstet Gynecol 1985;65:426-30.

intraoperative complications. Obstet Gynecol 1985;65:426-30.
4 Rodeck CH. In: Rodeck CH, Nicolaides KH, eds. Proceedings of the eleventh study group of the Roval College of Obstetricians and Gynaecologists. London: Roval College of Obstetricians and Roval College of Obstetricians ar

5 Turnbull AC, Mackenzie IZ. Second trimester amniocentesis and termination of pregnancy. $\mathrm{Br}$ Med Bull 1983;39:315-21.

6 Knott PD, Penketh RJA, Lucas MK. Uptake of amniocentesis in women aged 38 years or more by their expected date of delivery: a two year retrospective study. $\mathrm{Br}$ f Obstel Gynaecol (in press). Old JM, Ward RHT, Petrou M, et al. First trimester fetal diagnosis for haemoglobinopathies: three cases. Lancet 1982;ii:1413-6.

8 Ward RHT, Modell B, Petrou M, et al. Method of sampling chorionic villi in first trimester of pregnancy under guidance of real time ultrasound. $\mathrm{Br}$ Med J 1983;286: 1542-4.

9 Baird PA, Sadovnick AD, McGillivray BC. Temporal changes in the utilisation of amniocentesis for prenatal diagnosis by women of advanced maternal age 1976-1983. Prenat Diagn 1985;5: 191-8.

10 Gustavii B. Chorionic biopsy and miscarriage in the first trimester. Lancet 1984;i:562

11 Modell B. Chorionic villus sampling. Evaluating safety and efficiency. Lancet 1985;i:737-40.

(Accepted 23 June 1986)

\section{SHORT REPORTS}

\section{Public awareness of testicular cancer and the value of self examination}

Early presentation of cancer of the testis is an important factor in the selection of treatment and prognosis. ${ }^{1}$ Poor health education in some patients is thought to contribute to their undue delay before seeking medical advice. ${ }^{2}$ We report a survey of public attitudes to the disease.

\section{Subjects, methods, and results}

A postal questionnaire was sent to 500 men aged 21 to 65 , selected on the basis of a better education and higher socioeconomic state than the public at large. Analysis was performed on achieving a $79 \%$ response rate $(n=395)$. The table summarises the results.

Nearly one third of respondents $(126 ; 32 \%)$ were unaware that men may get cancer of the testicle, and $342(87 \%)$ did not know the age group affected. Of the latter, $182(46 \%)$ admitted no knowledge and $160(41 \%)$ considered it a cancer of old age. Questioned specifically about the $15-40$ year age group, only five respondents $(1 \cdot 3 \%)$ knew that it was a common type of tumour between these ages, $22(6 \%)$ were partially correct, but $367(93 \%)$ were unaware of its relative prevalence at this age. Concerning possible symptoms or signs, 77 respondents (19\%) suggested a lump or swelling as an important finding. A further $13(3 \%)$ reported other correct features but not a lump. Most $(284 ; 72 \%)$ admitted to having no knowledge of possible symptoms, and $18(5 \%)$ responded with various incorrect answers, such as problems with potency or micturition. Only 18 respondents $(5 \%)$ thought testicular cancer curable in $75-100 \%$ of cases. A further $38(10 \%)$ considered that half could be cured, but $336(85 \%)$ of those questioned were not aware of the real cure prospects, including $49(12 \%)$ who thought that treatment would be unsuccessful. A testicular self examination procedure was unknown to $365(92 \%)$ of the men, and only $5(1 \cdot 3 \%)$ performed the examination regularly. A total of $324 \mathrm{men}(82 \%)$ had never examined their testicles in a formal manner. Finally, 357 men $(90 \%)$ confirmed that they would be interested in more information about cancer of the testis.

Public's knowledge of testicular cancer and self examination of testis (395 respondents). Figures are numbers (percentages) of respondents

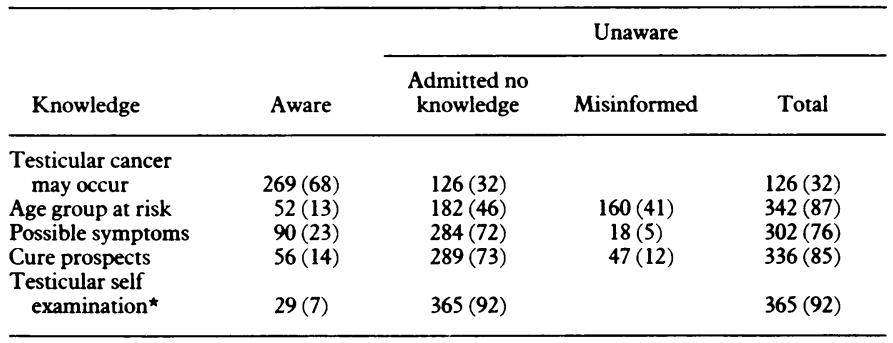

^Five men $(1 \cdot 3 \%)$ performed self examination regularly. 